Available online at www.sciencedirect.com

Science (ด) DiREct

Computers \& Education xxx (2005) xxx-xxx
COMPUTERS \&

EDUCATION

www.elsevier.com/locate/compedu

\title{
Measuring perceived sociability of computer-supported collaborative learning environments
}

\author{
Karel Kreijns ${ }^{\text {a,* }}$, Paul A. Kirschner ${ }^{b}$, Wim Jochems ${ }^{b}$, Hans van Buuren ${ }^{c}$ \\ a Open Universiteit Nederland, Ruud de Moor Center for Teacher Professionalization, P.O. Box 2960, \\ 6401 DL Heerlen, The Netherlands \\ ${ }^{\mathrm{b}}$ Open Universiteit Nederland, Educational Technology Expertise Center (OTEC), Heerlen, The Netherlands \\ c Open Universiteit Nederland, Department of Psychology, Heerlen, The Netherlands
}

Received 7 February 2005; accepted 13 May 2005

\begin{abstract}
Most asynchronous computer-supported collaborative learning (CSCL) environments can be characterized as functional environments because they focus on functional, task-specific support, often disregarding explicit support for the social (emotional) aspects of learning in groups which are acknowledged by many educational researchers to be essential for effective collaborative learning. In contrast, sociable CSCL environments emphasize the social (emotional) aspects of group learning. We define sociability as the extent to which a CSCL environment is perceived to be able to facilitate the emergence of a sound social space with attributes as trust and belonging, a strong sense of community, and good working relationships. Specific environmental characteristics, which we have designated social affordances, determine sociability.

This explorative study deals with the construction and preliminary validation of a self-reporting (Dutch language) Sociability Scale for determining the perceived degree of sociability of CSCL environments. It is one-dimensional Scale consisting of 10 items and has an internal consistency of 0.92 . It was further validated on the basis of a well-developed nomological network. The results of the explorative study are promising and show that the sociability scale has the potential to be useful as a measure for perceived sociability. (c) 2005 Elsevier Ltd. All rights reserved.
\end{abstract}

\footnotetext{
${ }^{*}$ Corresponding author.

E-mail address: karel.kreijns@ou.nl (K. Kreijns).
} 


\section{ARTICLE IN PRESS}

Keywords: Architectures for educational technology system; Computer-mediated communication; Cooperative/ collaborative learning; Distributed learning environments

\section{Introduction}

The emergence of computer-mediated worldwide networks has enabled a shift from collaborative learning in contiguous learning groups to collaborative learning in asynchronous distributed learning groups (DLGs) by utilizing asynchronous and synchronous computersupported collaborative learning (CSCL) environments connected to these networks. To achieve such learning many developed countries have embraced both of these modes making use of synchronous techniques based upon broadband technology applications such as NetMeeting $^{\circledR}$ and asynchronous techniques based upon lean text-based technologies for chat, discussion forums, and e-mail. Developing countries, however, do not have this luxury and are relegated to primarily using the latter. Also, the demographics of life-long learners (i.e., post initial learners, often with a job, a family, or both) necessitate the organization, planning, and instrumentation of learning in a temporally distributed manner making asynchronous CSCL also both attractive and necessary in developed countries. In other words, the requirements of worldwide learning and life long learning, both of which fulfill the requirements imposed by the current and future demands of today's knowledge society, favor the use of asynchronous CSCL environments.

The communication between learners and instructors in asynchronous CSCL environments is mediated through subsystems (e-mail, discussion forums, chat) embedded or integrated within the CSCL environment. Although the CSCL environments support social interaction and collaboration, empirical research and field observation show findings that are not always positive about their working (Hallet \& Cummings, 1997; see also Heath, 1998). Hobaugh (1997), for example, observed that inadequate group dynamics amongst group members in online groups "is often the major cause of ineffective group action; unfortunately, either very little attention is devoted to it, or it is not well understood by instructors or students, or both" ('Planning for Interaction'). Indeed, educational researchers predominantly focus on the support of social interaction aimed at cognitive processes for collaborative learning (the educational dimension of social interaction) and less on the support of social interaction aimed at socio-emotional processes underlying group dynamics; the so-called social (psychological) dimension of social interaction. Moreover, the majority of these researchers - consciously or unconsciously - take for granted that group dynamic processes occur in CSCL environments, just as in face-to-face settings, although this may be not true. In addition, it appears that researchers think that encouragement for group dynamics is not needed because they believe that the only thing learners want to do is to learn and everything that distracts from that (i.e., group dynamics) should be avoided. Finally, there is also a group of researchers who forget to pay attention to group dynamics because they are not aware of the importance of group dynamics and its implications for collaborative learning. In sum, most researchers simply forget, neglect or ignore to study and support the group dynamics within the CSCL environment. As a result functional CSCL environments are developed. This conclusion is 


\section{ARTICLE IN PRESS}

confirmed by Cutler (1996) who remarked that the "current literature surrounding CMC (computer-mediated communication) is almost entirely task-based and focused on cost, efficiency, and productivity with little attention given either to the changes effected on the people or to the social relations created from using the communication technologies" (p. 320). In general, typical functional CSCL environments are those where the CMC subsystem is the CSCL environment.

However, a growing number of researchers from a variety of disciplines (e.g., computersupported collaborative work, social psychology, organizational behavior) point out that this functional perspective alone is a very limited one. Forgetting, neglecting or ignoring social psychological processes such as group forming, establishing group structures and sustaining social relationships is considered as a pitfall (see Kreijns, Kirschner, \& Jochems, 2003). Sproull and Faraj (1997) stressed that "People on the net are not only solitary information processors but also social beings. They are not only looking for information; they are also looking for affiliation, support and affirmation. Thinking of people on the net as social actors evokes a metaphor of a gathering. Behaviors appropriate at the gathering include chatting, discussing, arguing, and confiding. People go to a gathering to find others with common interests and talk with or listen to them. When they find a gathering they like, they return to it again and again" (p. 38). Donath (1997) advocates the design of on-line social environments. She believes that in order to foster the development of vibrant and viable online communities, the environment must provide the means to communicate social cues and information. This means that users of an environment must be able to perceive the social patterns of activity and affiliation and the community using it must be able to develop a fluid and subtle cultural vocabulary. In other words, what we actually need are sociable CSCL environments, that is CSCL environments with both educational functionality and social functionality. Such sociable CSCL environments not only fulfill the learning needs of the students, but also fulfill their social (psychological) needs, thereby making a complete learning experience.

Sociable CSCL environments enable and facilitate socio-emotional processes such as affiliation and getting to know each other which aim at developing interpersonal relationships, trust building, social cohesiveness and a sense of community and the emergence of a sound social space. Johnson and Johnson (1989) see interpersonal trust as a major factor enabling effective collaboration: "To disclose one's reasoning and information, one must trust the other individuals involved in the situation to listen with respect" (p. 72). Forsyth (1990), Shaw (1981), and Guzzo and Dickson (1996) all have found social cohesiveness positively mediates group performance. Wegerif (1998), for example, noted that "forming a sense of community, where people feel they will be treated sympathetically by their fellows, seems to be a necessary first step for collaborative learning. Without a feeling of community people are on their own, likely to be anxious, defensive and unwilling to take the risks involved in learning" (p. 48). Gunawardena (1995) argues that online constructivist learning environments may promote collaborative learning "only if participants can relate to one another, share a sense of community and a common goal. The development of social presence [social presence will be explained hereafter] and a sense of online community becomes the key to promoting collaborative learning and knowledge building" (p. 164).

Within distance educational settings such as those found at open universities (e.g., the Open Universiteit Nederland), the application of sociable CSCL environments can be a critical success fac- 


\section{ARTICLE IN PRESS}

tor. When groups are formed in these settings, the group members do not initially know each other and the group has no history. Sociable CSCL environments can help to develop group dynamics in a positive direction, and thus reduce feelings of loneliness and isolation thereby reducing drop-out (Phillips, 1990; Rovai, 2001).

Our research on fostering and enhancing social interaction in (asynchronous) distance learning groups is aimed at the design and implementation of sociable CSCL environments. The research is based upon a theoretical framework (see Kreijns \& Kirschner, 2004; Kreijns, Kirschner, \& Jochems, 2002) encompassing:

1. the ecological approach to social interaction, comprising the concept of social affordances (Gaver, 1996; Gibson, 1986);

2. the concept of the sociability of CSCL environments (Kreijns et al., 2002); and

3. social presence theory (Gunawardena, 1995; Short, Williams, \& Christie, 1976; Tammelin, 1998; Tu, 2000, 2002; Tu \& McIsaacs, 2002).

It is beyond the scope of this article to discuss in full detail the first and last of these issues of the framework, but this discussion can be found in Kreijns et al. (2002) and Kreijns and Kirschner (2004). On the other hand, we cannot completely neglect these issues here since they are closely related to sociability and the need for a very precise distinction between perceived sociability and perceived social presence is of the utmost importance.

The sociability of CSCL environments refers to how CSCL environments can differ in their ability to facilitate the emergence of a social space; the human network of social relationships between group members which is embedded in group structures of norms and values, rules and roles, beliefs and ideals. To express the differences in ability in the creation of a social space, the term sociability is introduced. We define sociability as the extent to which a CSCL environment is perceived to be able to facilitate the emergence of a sound social space. We designate a social space to be 'sound' if the social space is characterized by affective work relationships, strong group cohesiveness, trust, respect and belonging, satisfaction, and a strong sense of community. In our perspective, sociability is determined by specific environmental characteristics, which we have designated social affordances (Kreijns et al., 2002).

In order to clarify the concept of social affordances a canonical example of a real life social affordance device is given here. The water cooler is a place where people gather and have casual conversations and communicate informally with each other. These impromptu encounters offer serendipitous moments to exchange not only task related information but also socioemotional information. The water cooler becomes a place where people can get to know each other and experience whom they can trust, who the experts are, what the interests of others are, and so on. In sociable CSCL environments, electronic equivalents of the water cooler should be integrated in these environments. These electronic social affordance devices provide group awareness information to the group members; up-to-the-minute understanding of the whereabouts of the members of the group in the form of where they are and what they are doing at the moment the information is inspected (cf., Gutwin, 1997). This creates a feeling of being in each other's proximity. Of course, this is only true when group members are online. When members are offline, the updating is stopped, but the information gathered is 


\section{ARTICLE IN PRESS}

still available for inspection (i.e., the information can be interpreted as traces or footprints). Group awareness information is usually presented in a graphical manner and different types of group awareness information can be displayed simultaneously (Kreijns et al., 2002). Finally, easy access to the CMC subsystem is warranted for approachable communication.

We hypothesize that sociability is a factor which influences social interaction: the greater the sociability of an environment, the more likely it is that social interaction will take place and that it will result in the emergence of a sound social space.

Social presence is another factor influencing social interaction (Gunawardena, 1995; Tammelin, 1998; Tu, 2000, 2002; Tu \& Isaacs, 2002). Short et al. (1976) originally define social presence as the "degree of salience of the other person in the interaction and the consequent salience of the interpersonal relationships" (p. 65). We define social presence as the perceived degree of illusion that the other in the communication appears to be a 'real' physical person in either an immediate (i.e., real time or synchronous) or a delayed (i.e., time-deferred or asynchronous) communication episode. Tu (2000), linking social learning theory to the concept of social presence, contends that social presence "is required to enhance and foster online social interaction, which is the major vehicle of social learning" (p. 27). If "social presence is low, the foundation of social learning, social interaction, does not occur" (p. 30). Rourke, Anderson, Garrison, and Archer (1999) point to two important functions of social presence in their community of inquiry model: (1) it supports "cognitive objectives through its ability to instigate, sustain, and support critical thinking" (p. 52); (2) it supports "affective objectives by making group interactions appealing, engaging, and thus intrinsically rewarding" (p. 52).

Group awareness is hypothesized to be one of the factors that is contributing to the perception of social presence because it - by definition - presents dynamic information about the group members or their traces thereby enhancing the illusion of the 'presence' of the other. In a sense it can be argued that sociability contributes to social presence because group awareness is part of the social affordance device, which, in turn, determines sociability.

Because our framework emphasizes the promotion of social interaction in the social (psychological) dimension, it complements existing pedagogical techniques that emphasize social interaction in the educational dimension. The framework acknowledges that in order to create a sound social space, the environment (i.e., the CSCL environment), the people 'inhabiting' the environment (i.e., the learners/group members), and the activities they carry out (i.e., those learning activities that are determined by the pedagogical techniques) are all equally important. The theoretical framework uses a number of variables that affect social interaction in CSCL environments. Social interaction, in turn, affects the creation of a social space. Fig. 1 summarizes the relationships between the variables and pinpoints the relative importance of sociability in the whole picture.

To study the various relationships an instrument that measures the perceived sociability of CSCL environments is needed. Such an instrument will be helpful for designers and implementers of CSCL environments by allowing them to determine whether and to what extent an environment has or lacks social functionality and whether and which changes in the environment lead to its improvement. Since the current body of literature revealed that there is no instrument available that measures the sociability of CSCL environments, we needed to devel- 


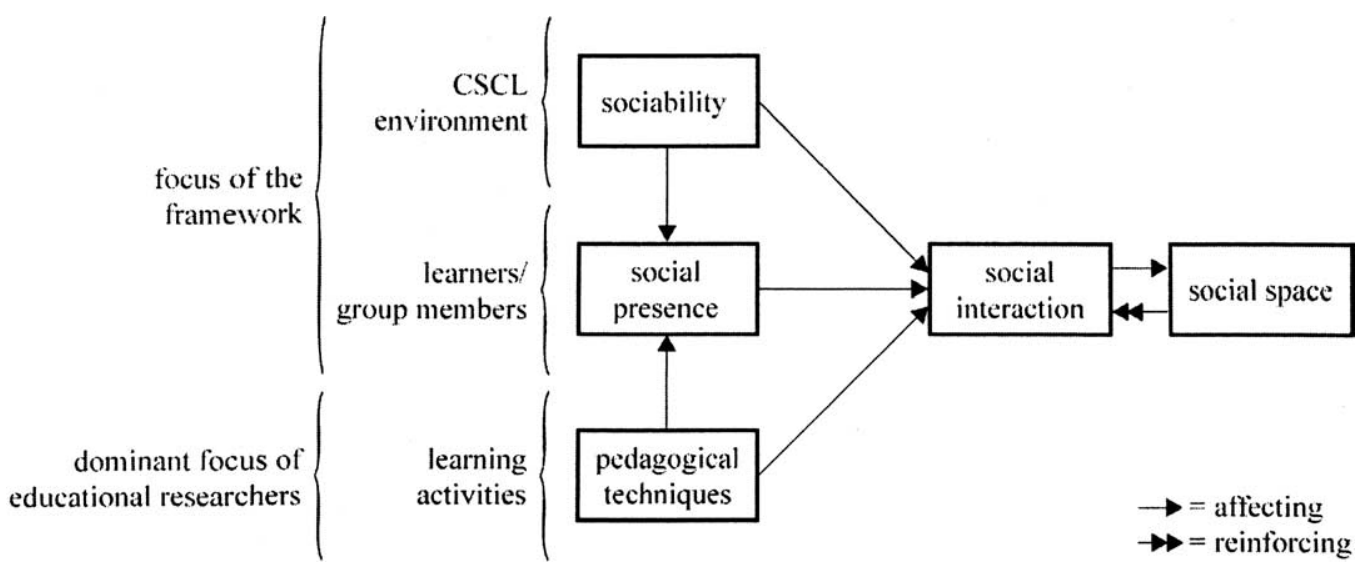

Fig. 1. Relationships between the variables sociability, social presence, pedagogical techniques, social interaction, and social space.

op and validate such an instrument. The (refined) Sociability Scale is presented in the next section.

\section{The Sociability Scale}

The Sociability Scale is a self-reporting questionnaire for measuring the perceived sociability of a CSCL environment. This scale consists of 10 items (see Table 1). The four last columns show statistical data discussed in Section 5.

Table 1

The Sociability Scale

\begin{tabular}{|c|c|c|c|c|}
\hline $\begin{array}{l}\text { No. } \\
\text { item }\end{array}$ & Item & $M$ & SD & $\begin{array}{l}\text { Factor } \\
\text { sociability }\end{array}$ \\
\hline 1 & This CSCL environment enables me to easily contact my team mates & 3.30 & 1.03 & 0.77 \\
\hline 2 & I do not feel lonely in this CSCL environment & 2.90 & 1.18 & 0.69 \\
\hline 3 & $\begin{array}{l}\text { This CSCL environment enables me to get a good impression of my team } \\
\text { mates }\end{array}$ & 2.58 & 0.98 & 0.80 \\
\hline 4 & This CSCL environment allows spontaneous informal conversations & 2.75 & 1.14 & 0.68 \\
\hline 5 & This CSCL environment enables us to develop into a well performing team & 2.76 & 1.05 & 0.80 \\
\hline 6 & $\begin{array}{l}\text { This CSCL environment enables me to develop good work relationships } \\
\text { with my team mates }\end{array}$ & 3.19 & 1.05 & 0.84 \\
\hline 7 & This CSCL environment enables me to identify myself with the team & 2.96 & 1.07 & 0.79 \\
\hline 8 & I feel comfortable with this CSCL environment & 3.44 & 1.06 & 0.83 \\
\hline 9 & This CSCL environment allows for non-task-related conversations & 3.61 & 0.99 & 0.69 \\
\hline 10 & $\begin{array}{l}\text { This CSCL environment enables me to make close friendships with my } \\
\text { team mates }\end{array}$ & 2.49 & 1.13 & 0.73 \\
\hline
\end{tabular}

Note. Judgments were made on 5 -point Likert scales $(1=$ not applicable at all; $2=$ rarely applicable; $3=$ moderately applicable; $4=$ largely applicable $; 5=$ totally applicable). 


\section{ARTICLE IN PRESS}

\section{Method}

\subsection{Participation}

Data were collected from students in three distance education courses at the Open Universiteit Nederland (OUNL). Thirty-five students (25 males, 10 females) from four higher education institutions participated in the first 'course' Virtual Environmental Consultancy (VEC) of the Department of Natural Sciences and used eRoom ${ }^{\circledR}$ version 5.4 (http://www.eroom.com) as their CSCL environment. All participants were divided into eight groups of three (1 group), four (6 groups), or eight (1 group).

The two other courses were taken from the Statistics Education Innovation Project at the Department of Psychology. Thirty-eight adult undergraduates (6 male and 32 female) enrolled in the first course were divided into seven groups of five (4 groups) or six (3 groups). Due to non-starters ( 2 female) and dropouts ( 2 male, 8 female) groups changed. Ultimately there were seven groups: four groups of 3 students, one group of 4 students and two groups of 5 students. One hundred and thirteen adult undergraduates (24 male and 79 female) enrolled in the second course and were divided into 18 groups of four ( 8 groups), five (1 group), eight ( 8 groups), or 12 (1 group). Here too, due to non-starters ( 6 females) and dropouts ( 4 males, 10 females) groups changed. Ultimately there were 18 groups: three groups of 2 students, one group of 3 students, three groups of 4 students, two groups of 5 students, four groups of 6 students, two groups of 7 students, and three groups of 8 students. In both of these courses students made use of StudyNet, the CSCL environment of the OUNL. In StudyNet, asynchronous communication is made available through newsgroups and real-time communication via Microsoft Netmeeting ${ }^{\circledR}$.

\subsection{Procedure}

The Virtual Environmental Consultancy course lasted 14 weeks in which there were three faceto-face meetings, namely a kick-off meeting at the start of the course, an evaluation meeting halfway through the course, and a closing meeting at the end of the course. The questionnaire including all the measures was administered electronically (using Dipolar Professional Quest software, release 2.2, http://www.dipolar.com.au) just after the second face-to-face meeting. From the 35 students 11 students $(31.4 \%)$ responded to the questionnaire from which 9 students $(25.7 \%)$ responded to all items.

The first course from the Statistics Education Innovation Project lasted 18 weeks in which three face-to-face meetings were organized. The same electronic questionnaire was launched. From the number of students that actually participated ( 26 students; 38 initial students minus the number of non-starters minus the number of drop-outs) $18(69.2 \%)$ students responded to the questionnaire.

The second course from the Statistics Education Innovation Project had a variable length. Some groups had 10 months to complete the course while the remaining groups had six. At the time the questionnaire was launched, slow groups were still studying while the fast groups had completed the course. From the number of participants (93 students; 113 initial students minus the number of non-starters and minus the number of dropouts), 50 (53.8\%) responded. Two students who dropped out also returned the questionnaire. The total number of respondents is, therefore, 52 . 


\section{ARTICLE IN PRESS}

\subsection{Instrumentation}

In our validation process, we used five measures that deal with constructs that are related to the sociability construct. These measures are:

1. Social Space Scale (Kreijns, Kirschner, Jochems, \& Van Buuren, 2004),

2. Social Presence Indicators (Gunawardena, 1995),

3. Social Presence Scale (Gunawardena \& Zittle, 1997),

4. Work-Group Cohesiveness Index (Price \& Mueller, 1986),

5. Group Atmosphere Scale (Fiedler, 1962, 1967).

We briefly describe each of these measures in the next sub-sections.

\subsubsection{The Social Space Scale}

The Social Space Scale (Kreijns et al., 2004) measures the degree of the perceived quality of the social space that exists in asynchronous distributed learning group. The scale has two dimensions: Positive Group Behavior and Negative Group Behavior. Each dimension contains 10, 5-point Likert scale items. Examples of the test items are: 'Group members felt free to criticize the ideas, statements, and/or opinions of others', 'Group members gave personal information on themselves', and 'Group members grew to dislike others'. Because sociability contributes to social space, we expected a moderate correlation between the Social Space Scale and the Sociability Scale. A high correlation would mean that the Sociability Scale is measuring aspects of social space (or vice versa). Like the Sociability Scale, the Social Space Scale was constructed and validated in an explorative study.

\subsubsection{The Gunawardena Social Presence Indicators}

Gunawardena (1995) used a questionnaire of a total of 17, 5-point bipolar scale items (see Appendix 1) to assess a range of feelings students have towards CMC. She equated this to the perceived social presence. In this study, we refer to these bi-polar scale items as the Social Presence Indicators. We expected a high correlation between this measure and the Sociability Scale because we believed the test items measure, amongst other things, many aspects of the sociability of CMC (e.g., see the item 'sociable-unsociable'). The items of the scale were translated into Dutch.

\subsubsection{The Gunawardena and Zittle Social Presence Scale}

The Gunawardena and Zittle (1997) Social Presence Scale is an alternative scale for measuring social presence and, thus, can be used interchangeably with the Social Presence Indicators. The Social Presence Scale consists of 14, 5-point Likert-scale items (see Appendix 2). Examples of test items are: 'I felt comfortable conversing through this text-based medium' and 'The moderators created a feeling of an on-line community'. We slightly adapted the items of their Social Presence Scale to fit our particular setting and then translated them into Dutch. For the same reasons as with the Social Presence Indicators, we expected a high correlation between the Social Space Scale and the Sociability Scale. In this study, we did not consider' the items 9, 10, and 11, because they go beyond the scope of our interest (i.e., the sociability construct). 


\section{ARTICLE IN PRESS}

\subsubsection{The Price and Mueller Work Group Cohesion Index}

Price and Mueller (1986) developed their Work Group Cohesion Index to measure workgroup cohesion in an organizational context. The Work Group Cohesion Index consists out of five, 5-point Likert scale items (see Appendix 3). Sociability is affecting social space, and an attribute of social space is social cohesiveness. Therefore, we expected a moderate correlation between the Sociability Scale and the Work Group Cohesion Index. The items of this measure were also translated into Dutch.

\subsubsection{Fiedler's Group Atmosphere Scale}

Fiedler (1967) developed the Group Atmosphere Scale, which makes use of an 8-point scale for determining the atmosphere in a group as perceived by the group members (see Appendix 4). Instead of using 8-point scales we used 5-point scales to concur with the other scales used. Sociability is affecting group atmosphere (social climate). We, thus, expected a moderate correlation between our Sociability Scale and the Group Atmosphere Scale. Nevertheless, since the Group Atmosphere Scale is also very similar to the Social Presence Indicators, we expected the correlation to be of the same magnitude as the correlation between Sociability Scale and Social Presence Indicators. The items of the Group Atmosphere Scale were translated into Dutch.

\section{Construction and refinement of the raw Sociability Scale}

\subsection{Constructing the raw Sociability Scale}

When we constructed the raw Sociability Scale, we had no systematic approach in mind other than that we were guided by the literature (mainly the computer-supported cooperative work and human-computer interaction literature, e.g., Donath, 1997) to determine what good sociability consists of. Additionally, the construction of the test items of the Sociability Scale was based upon our approach to increase sociability, that is, group awareness, communication, and potential for facilitating the creation of a community (of learning). As a result, the raw Sociability Scale was composed of 34 test items addressing these elements. This number of items deliberately overrepresented the sociability construct. We intended to remove redundant items in a later refinement process which would also remove those items that were psychometrically 'rejected'. The advantage of such a method was that we could postpone the decision of which items to include in the final Sociability Scale up to the moment that we would have gained a clearer picture of the meaning of the various items.

\subsection{Removing test items of the Sociability Scale}

The raw Sociability Scale was refined in three steps. In the first step, 24 items from the 34 initial test items were removed because they either addressed a utility aspect (feature) such as 'This CSCL environment enabled me to see who of the group members are logged in' or usability aspect such as 'This CSCL environment has easy access to the communication media'. Although these items can be associated with sociability, they are generally used for assessing the usefulness (Shneiderman, 1998) of a CSCL environment. Therefore, we decided not to include the items in the Sociability Scale for further analyses since these utility/usability items would be confounded with sociability items. 


\section{ARTICLE IN PRESS}

In the second step, a Principal Component Analysis (no rotation) was performed on the remaining test items. This step revealed that the Sociability Scale is one-dimensional (using the scree test of Cattell, 1966). The step was also used to remove the few test items that did not load higher than 0.40 (see for this criterion, Stevens, 1992) exclusively on the first component (removed zero items).

The third and last step was to reduce the remaining test items further to 10 without losing too much of explained total variance (removed zero items, we already had 10 items).

The resulting refined Sociability Scale is depicted in Table 1. The three last columns show respectively mean $M$, standard deviation SD, and loading on the first and only component (a new Principal Component Analysis (no rotation) was performed on the 10 final test items). The component explained $58.52 \%$ of the total variance.

\section{Results}

\subsection{Internal consistency and validity}

Cronbach's $\alpha$ for the refined Sociability Scale was 0.92 revealing a high internal consistency. Content validity of the Sociability Scale was established via face-validity. The items were developed based upon a search in the literature regarding social interaction via CMC, group development and group dynamics, social presence, trust building, and creating sense of community.

We applied a Pearson bi-variate correlation (two-tailed) analysis on the aggregate scores of the test items of the Sociability Scale and each of the measures Social Space Scale, Social Presence Indicators, Social Presence Scale, Work Group Cohesion Index, and Group Atmosphere Scale. Table 2 depicts the correlations. As can be seen, correlations are, with respect to both the strength and direction, as expected. The low and negative correlation between the Negative Group Behavior-dimension of the Social Space Scale and the Sociability Scale is explained by the observation that the Sociablity Scale does not measure negative experiences as does the Social Space Scale (Kreijns et al., 2004).

Finally, we applied Principal Component Analysis using Varimax rotation on the 10 test items of the refined Sociability Scale and the 20 test items of the Social Space Scale. We restricted the

Table 2

Pearson bi-variate correlation coefficients between the different scales

\begin{tabular}{lr}
\hline Measure & Sociability Scale \\
\hline Social Space Scale & $0.60^{* *}$ \\
$\quad$ Positive group behavior & $-0.08^{* *}$ \\
$\quad$ Negative group behavior & $0.83^{* *}$ \\
Social Presence Indicators & $0.85^{* *}$ \\
Social Presence Scale & $0.60^{* *}$ \\
Work Group Cohesion Index & $0.78^{* *}$ \\
Group Atmosphere Scale & \\
\hline
\end{tabular}

** $p<0.01$, two-tailed. 
Table 3

Factor analysis of the scores of the items of the Social Space Scale and the Sociability Scale

\begin{tabular}{|c|c|c|c|c|}
\hline $\begin{array}{l}\text { No. } \\
\text { item }\end{array}$ & Item & $\begin{array}{l}\text { Factor 1: } \\
\text { Sociability }\end{array}$ & $\begin{array}{l}\text { Factor 2: } \\
\text { Positive } \\
\text { group } \\
\text { behavior }\end{array}$ & $\begin{array}{l}\text { Factor 3: } \\
\text { Negative } \\
\text { group } \\
\text { behavior }\end{array}$ \\
\hline
\end{tabular}

Social Space Scale: positive group behavior

1 Group members felt free to criticize ideas, statements, and/ 0.01

0.76

$-0.04$ or opinions of others

3 We reached a good understanding on how we had to function

5 Group members ensured that we kept in touch with each

0.10

0.80

0.06 other

7 We worked hard on the group assignment

0.21

0.75

$-0.07$

I maintained contact with all other group members

Group members gave personal information on themselves

0.44

The group conducted open and lively conversations and/or discussions

Group members took the initiative to get in touch with

0.32

0.78

$-0.07$ others

Group members spontaneously started conversations with

0.73

$-0.08$ others

\section{Social Space Scale: negative group behavior}

2 Group members felt that they were attacked personally

when their ideas, statements and/or opinions were criticized $^{\mathrm{a}}$

$4 \quad$ Group members were suspicious of others ${ }^{\mathrm{a}}$

I did the lion's share of the work ${ }^{\mathrm{a}}$

\section{8}

Group members obstructed the progress of the work ${ }^{\mathrm{a}}$

Group members were unreasonable ${ }^{\mathrm{a}}$

Group members disagreed amongst each other ${ }^{\mathrm{a}}$

The group had conflicts ${ }^{\mathrm{a}}$

Group members gossiped about each other ${ }^{\mathrm{a}}$

Group members did not take others seriously ${ }^{\mathrm{a}}$

$-0.02$

0.32

$-0.13$

$-0.05$

$-0.25$

$-0.09$

0.08

0.53

$-0.10$

0.56

$-0.07$

\section{Sociability Scale}

1 This CSCL environment enables me to easily contact my team mates

2 I do not feel lonely in this CSCL environment

3 This CSCL environment enables me to get a good impression of my team mates

4 This CSCL environment allows spontaneous informal conversations

5 This CSCL environment enables us to develop into a well performing team

0.75

0.15

0.49 relationships with my team mates

0.30

$-0.02$ 


\section{ARTICLE IN PRESS}

\begin{tabular}{lllll} 
Table 3 (continued $)$ & & \\
\hline $\begin{array}{l}\text { No. } \\
\text { item }\end{array}$ & Item & $\begin{array}{l}\text { Factor 1: } \\
\text { Sociability }\end{array}$ & $\begin{array}{l}\text { Factor 2: } \\
\text { Positive } \\
\text { group } \\
\text { behavior }\end{array}$ & $\begin{array}{l}\text { Factor 3: } \\
\text { Negative } \\
\text { group } \\
\text { behavior }\end{array}$ \\
\hline 7 & $\begin{array}{l}\text { This CSCL environment enables me to identify myself with } \\
\text { the team }\end{array}$ & $\mathbf{0 . 6 2}$ & $\mathbf{0 . 5 0}$ & -0.02 \\
8 & $\begin{array}{l}\text { I feel comfortable with this CSCL environment } \\
\text { This CSCL environment allows for non-task-related } \\
\text { conversations } \\
\text { This CSCL environment enables me to make close } \\
\text { friendships with my team mates }\end{array}$ & $\mathbf{0 . 7 7}$ & 0.29 & 0.15 \\
10 & $\mathbf{0 . 6 8}$ & 0.18 & 0.15 \\
& & 0.05 & -0.16 \\
\hline
\end{tabular}

Note. Bold numbers are loadings $>0.40$; roman numbers are loadings $\leqslant 0.40$.

a These items were reverse coded for analysis.

extraction to only three components because the purpose of this analysis was not to reveal new components, but rather to confirm the uniqueness of the scales with respect to each other. Because the Social Space Scale has two dimensions and the Sociability Scale only one, the restriction was set to three. By uniqueness we mean that although the scales may be related (see correlation data in Table 2), they do not measure the same phenomena. The result of this analysis is given in Table 3. The loadings on the component show that the two scales measure two different phenomena.

\section{Weakness of the study}

The validation of the Sociability Scale has some weak points. First, the number of cases was 79. A general rule of thumb is that there must be at least 5 (Gorsuch, 1983) to 10 cases (Nunnally, 1978) per item. The raw Sociability Scale contained 34 items, meaning that we needed 170 up to 340 cases to derive this measure. However, as the raw Sociability Scale contained 24 items related to utility/usability aspects rather than sociability, they could be removed before any analyses. The actual scale we deal with contained only 10 items and, thus, the number of cases required can be much lower: 50 up to 100 cases. In that perspective 79 cases will do.

Second, there were three samples (VEC, first statistics course, second statistics course), that have been collapsed in order to obtain the 79 cases. We agree that these samples have different characteristics (e.g., time aspects, CSCL environments, task type) which mean that they actually cannot be collapsed into one big sample. Indeed, a series of one-way ANOVA's revealed that although the samples VEC and first statistics course are comparable, these two samples are not comparable with the sample of the second statistics course. However, as this study is exploratory, we did collapse the samples to obtain a higher number of cases.

Finally, we used the same cases for the Principal Component Analysis on the items of the refined Sociability Scale and the Social Space Scale. This means that the result (Table 3) might take advantage of the chance characteristic of the 79 cases from which both scales were derived. 


\section{ARTICLE IN PRESS}

\section{Conclusion}

Social interaction is considered to be the dominant factor affecting collaboration in groups and thus learning performances in those groups. In addition, social interaction is also a dominant factor in group forming and group dynamics. That is, the social interaction found in group learning is also responsible for developing new groups into mature well performing groups in which an affective structure is established - characterized by social relationships, social cohesiveness and a sense of community. These are the attributes of a social space. A sound social space allows for open communication that is beneficial for the collaborative activities and the exchange of essential information.

If we are to design and develop technologically, educationally, and socially functional CSCLenvironments we need to not only consider these aspects in our designs and implementations (the designer's perspective), but we also need to determine how the users (our students) perceive these environments. The Sociability Scale presented here on the one hand operationalizes the different aspects of sociability so that the designer (technical and educational) can take account of the different aspects of sociability in her/his design. On the other hand it gives the designers/developers a tool with which they can accurately measure whether their work has borne fruit.

For this reason it is important that factors are identified that foster social interaction for socio-emotional processes in a CSCL environment or that the CSCL environment in and by itself adds to an increase of this kind of social interaction, for example, through the incorporation of social affordance devices that determine the sociability of the environment. But the effects of these latter strategies need to be measured in order to determine the effectiveness of each on sociability and thus on the creation of a sound social space. It is important to develop a measurement instrument to determine the sociability of an environment, i.e., the Sociability Scale. The Sociability Scale will, in our case, help to develop the right social affordance devices, in the sense that they are indeed effective in their contribution to the sociability.

This article presented the development and validation of a Sociability Scale. The results suggest that the Sociability Scale has the potential to be useful as a measure for assessing the sociability of CSCL environments. Though the findings are very promising, further work based on a larger sample is warranted. As is the case with each (new) measurement instrument, continuous research is needed for further improvements of the instrument and our Sociability Scale is no exception in this practice.

\section{Acknowledgments}

The authors thank Hans van der Vleugel and Rolf van Geel for their comments on the methodological and statistical sections of the draft version of this paper, which have contributed to the quality of this article. 


\section{ARTICLE IN PRESS}

14

\section{Appendix 1}

The Gunawardena Social Presence Indicators

\begin{tabular}{rlll}
\hline No. item & Item $^{\text {a }}$ & $M$ & SD \\
\hline 1 & stimulating-dull & 3.73 & 1.13 \\
2 & personal-impersonal & 3.05 & 1.04 \\
3 & sociable-unsociable & 1.08 \\
4 & sensitive-insensitive & 3.20 & 0.91 \\
5 & warm-cold & 2.75 & 0.86 \\
6 & colorful-colorless & 1.06 \\
7 & interesting-boring & 2.97 & 1.04 \\
8 & appealing-not appealing & 2.92 & 1.12 \\
9 & interactive-non-interactive & 3.81 & 1.09 \\
10 & active-passive & 3.47 & 1.15 \\
11 & reliable-unreliable & 3.72 & 0.77 \\
12 & humanizing-dehumanizing & 3.44 & 0.93 \\
13 & immediate-non-immediate & 3.76 & 1.09 \\
14 & easy-difficult & 3.20 & 1.21 \\
15 & efficient-inefficient & 3.24 & 1.16 \\
16 & unthreatening-threatening & 3.46 & 0.68 \\
17 & helpful-hindering & 3.29 & 1.03 \\
\hline
\end{tabular}

Note. Judgements were made on 5 -point bipolar scales $(1=$ positive rating, $5=$ negative rating $)$.

${ }^{a}$ All items were reverse coded for analysis.

\section{Appendix 2}

The Gunawardena and Zittle Social Presence Scale (adapted)

\begin{tabular}{|c|c|c|c|}
\hline No. & Item & $M$ & SD \\
\hline 1 & Messages in the CSCL environment were impersonal ${ }^{\mathrm{a}}$ & 3.52 & 0.81 \\
\hline 2 & $\begin{array}{l}\text { The CSCL environment is a an excellent medium for social } \\
\text { interaction }\end{array}$ & 3.01 & 1.03 \\
\hline 3 & $\begin{array}{l}\text { I felt comfortable conversing through this text-based CSCL } \\
\text { environment }\end{array}$ & 3.70 & 0.85 \\
\hline 4 & $\begin{array}{l}\text { I felt comfortable introducing myself in the CSCL } \\
\text { environment }\end{array}$ & 3.61 & 0.95 \\
\hline 5 & $\begin{array}{l}\text { The introduction(s) enabled me to form a sense of on-line } \\
\text { community in which I was part of }\end{array}$ & 2.78 & 1.25 \\
\hline 6 & $\begin{array}{l}\text { I felt comfortable participating in discussions in the CSCL } \\
\text { environment }\end{array}$ & 3.67 & 0.89 \\
\hline 7 & The moderators created a feeling of an on-line community & 2.32 & 1.07 \\
\hline
\end{tabular}




\begin{tabular}{|c|c|c|c|}
\hline No. & Item & $M$ & SD \\
\hline 8 & $\begin{array}{l}\text { The moderators facilitated discussions in the CSCL } \\
\text { environment }\end{array}$ & 2.44 & 1.19 \\
\hline 9 & $\begin{array}{l}\text { Discussions in CSCL environments tend to be more } \\
\text { impersonal than face-to-face discussions }\end{array}$ & 2.78 & 1.00 \\
\hline 10 & $\begin{array}{l}\text { Discussions in CSCL environments are more impersonal } \\
\text { than audio teleconference discussions } \mathrm{s}^{\mathrm{a}}\end{array}$ & 2.95 & 1.00 \\
\hline 11 & $\begin{array}{l}\text { Discussions in CSCL environments are more impersonal } \\
\text { than video teleconference discussions } \mathrm{s}^{\mathrm{a}}\end{array}$ & 2.75 & 1.07 \\
\hline 12 & $\begin{array}{l}\text { I felt comfortable interacting with other participants in the } \\
\text { CSCL environment }\end{array}$ & 3.73 & 0.96 \\
\hline 13 & $\begin{array}{l}\text { I felt that my point of view was acknowledge by other } \\
\text { participants in the CSCL environment }\end{array}$ & 3.28 & 0.82 \\
\hline 14 & $\begin{array}{l}\text { I was able to form distinct individual impressions of some } \\
\text { participants even though we communicated only via this } \\
\text { text-based CSCL environment }\end{array}$ & 2.92 & 1.07 \\
\hline
\end{tabular}

Note. Judgements were made on 5-point Likert scales $(1=$ strongly disagree, $2=$ disagree, $3=$ agreeldisagree, $4=$ agree, $5=$ strongly agree). The items 9, 10, and 11 were not considered in this study.

a These items were reverse coded for analysis.

\section{Appendix 3}

The Price and Mueller Work Group Cohesion Index

\begin{tabular}{llll}
\hline No. & Item & $M$ & SD \\
\hline 1 & To what extent were your team mates friendly? $^{\mathrm{a}}$ & 3.95 & 0.64 \\
2 & To what extent were your team mates helpful? $^{\mathrm{a}}$ & 3.76 & 0.98 \\
3 & To what extent did your team mates take a personal interest in you? $^{\mathrm{a}}$ & 3.09 & 0.99 \\
4 & To what extent did you trust your team mates? $^{\mathrm{a}}$ & 4.16 & 0.74 \\
5 & To what extent do you look forward to working again with $^{\text {These team mates? }}$ & 3.11 & 1.14 \\
\hline
\end{tabular}

Note. Judgements were made on 5-point Likert scales.

Item 1: $1=$ very friendly, $2=$ quite, $3=$ somewhat, $4=$ very little, $5=$ not friendly at all.

Item 2: $1=$ very helpful, $2=$ quite, $3=$ somewhat, $4=$ very little, $5=$ not helpful at all.

Item 3: $1=$ very interested, $2=$ quite, $3=$ somewhat, $4=$ very little, $5=$ not interested at all.

Item $4: 1=$ a great deal, $2=$ quite a lot, $3=$ some, $4=$ very little, $5=$ no trust at all.

Item $5: 1=$ very much, $2=$ quit a bit, $3=$ some, $4=$ very little, $5=$ not at all.

a These items were reverse coded for analysis. 


\section{Appendix 4.}

The Fiedler Group Atmosphere Scale

\begin{tabular}{llll}
\hline No. item & Item & $M$ & SD \\
\hline 1 & warm-cold $^{\mathrm{a}}$ & 0.86 \\
2 & interesting-boring $^{\mathrm{a}}$ & 2.97 & 1.04 \\
3 & accepting-rejecting $^{\mathrm{a}}$ & 3.81 & 0.80 \\
4 & satisfying-frustrating $^{\mathrm{a}}$ & 3.73 & 1.08 \\
5 & enthusiastic-unenthusiastic $^{\mathrm{a}}$ & 3.06 & 1.15 \\
6 & productive-non-productive $^{\mathrm{a}}$ & 3.37 & 1.23 \\
7 & cooperative-uncooperative $^{\mathrm{a}}$ & 3.35 & 0.96 \\
8 & supportive-hostile $^{\mathrm{a}}$ & 3.67 & 0.78 \\
9 & successful-unsuccessful $^{\mathrm{a}}$ & 3.86 & 1.02 \\
\hline
\end{tabular}

Note. Judgments were made on 5 -point bipolar scales $(1=$ positive rating, $5=$ negative rating $)$.

a These items were reverse coded for analysis.

\section{References}

Cattell, R. B. (1966). The scree test for number of factors. Multivariate Behavioral Research, 1, $245-276$.

Cutler, R. H. (1996). Technologies, relations, and selves. In L. Strate, R. Jacobson, \& S. B. Gibson (Eds.), Communication and cyberspace: Social interaction in an electronic environment (pp. 317-333). Cresshill, NJ: Hampton Press, Inc.

Donath, J. S. (1997). Inhabiting the virtual city: The design of social environments for electronic communities. Unpublished doctoral dissertation, Massachusetts Institute of Technology, Cambridge, MA. Retrieved March 24, 2004, from ftp://ftp.media.mit.edu/pub/donath/VirtualCity.ps.

Fiedler, F. E. (1962). Leader attitudes, group climate, and group creativity. Journal of Abnormal and Social Psychology, 65, 308-318.

Fiedler, F. E. (1967). A theory of leadership effectiveness. New York: McGraw-Hill.

Forsyth, D. R. (1990). Group dynamics (2nd ed.). Pacific Grove, CA: Brooks \& Cole.

Gaver, W. W. (1996). Situating action II: affordances for interaction: the social is material for design. Ecological Psychology, 8(2), 111-129.

Gibson, J. J. (1986). The ecological approach to visual perception. Hillsdale, NJ: Lawrence Erlbaum (Original work published 1979).

Gunawardena, C. N. (1995). Social presence theory and implications for interaction and collaborative learning in computer conferences. International Journal of Educational Telecommunications, 1(2/3), 147-166.

Gunawardena, C. N., \& Zittle, F. (1997). Social presence as a predictor of satisfaction within a computer mediated conferencing environment. American Journal of Distance Education, 11(3), 8-25.

Gutwin, C. (1997). Workspace awareness in real-time distributed groupware. Unpublished doctoral dissertation, University of Calgary, Calgary, Canada.

Gorsuch, R. L. (1983). Factor analysis. Hillsdale, NJ: Lawrence Erlbaum.

Guzzo, R. A., \& Dickson, M. W. (1996). Teams in organizations: recent research on performance and effectiveness. Annual Review of Psychology, 47, 307-338.

Hallet, K., \& Cummings, J. (1997). The virtual classroom as authentic experience. In Proceedings of the annual conference on Distance teaching and learning: Competition-connection-collaboration (pp. 103-107). Madison, WI: University of Wisconsin-Madison. 
Heath, E. F. (1998). Two cheers and a pint of worry: an on-line course in political and social philosophy. Journal of Asynchronous Learning Networks, 2(1), 15-33, Retrieved March 24, 2004, from http://www.aln.org/publications/ ialn/v2nl/pdf/v2nlheath.pdf.

Hobaugh, C. F. (1997). Interactive strategies for collaborative learning. In Proceedings of the annual conference on Distance teaching and learning: Competition-connection-collaboration (pp. 121-125). Madison, WI: University of Wisconsin-Madison.

Johnson, D. W., \& Johnson, R. T. (1989). Cooperation and competition: Theory and research. Edina, MN: Interaction Book Company.

Kreijns, K., \& Kirschner, P. A. (2004). Designing sociable CSCL environments: applying interaction design principles. In P. Dillenbourg (Series Ed.) \& J. W. Strijbos, P. A. Kirschner, \& R. L. Martens (Vol. Eds.), Computer-supported collaborative learning: Vol. 3. What we know about CSCL... and implementing it in higher education (pp. 221-244). Boston, MA: Kluwer Academic Publishers.

Kreijns, K., Kirschner, P. A., \& Jochems, W. (2002). The sociability of computer-supported collaborative learning environments. Journal of Education Technology \& Society, 5(1), 8-22, Retrieved March 24, 2004, from http:// ifets.ieee.org/periodical/vol_1_2002/v_1_2002.html.

Kreijns, K., Kirschner, P. A., \& Jochems, W. (2003). Identifying the pitfalls for social interaction in computersupported collaborative learning environments: a review of the research. Computers in Human Behavior, 19(3), 335-353.

Kreijns, K., Kirschner, P. A., Jochems, W., \& Van Buuren, H. (2004). Measuring perceived quality of social space in distributed learning groups. Computers in Human Behavior, 20(5), 607-632.

Nunnally, J. C. (1978). Psychometric theory. New York: McGraw-Hill.

Phillips, C. (1990). Making friends in the electronic student lounge. Distance Education, 11(2), 320-333.

Price, J. L., \& Mueller, C. W. (1986). Handbook of organizational measurement. Marshfield, MA: Pitman Publishing Inc.

Rourke, L., Anderson, T., Garrison, D. R., \& Archer, W. (1999). Assessing social presence in asynchronous, text-based computer conferences. Journal of Distance Education, 14(3), 51-70.

Rovai, A. P. (2001). Classroom community at a distance: a comparative analysis of two ALN-based university programs. Internet and Higher Education, 4(2001), 105-118.

Shaw, M. E. (1981). Group dynamics: The psychology of small group behavior (3rd ed.). NewYork: McGraw-Hill.

Shneiderman, B. (1998). Designing the user interface: Strategies for effective human-computer interaction (3rd ed.). New York: Addison-Wesley.

Short, J., Williams, E., \& Christie, B. (1976). The social psychology of telecommunications. London: Wiley.

Sproull, L., \& Faraj, S. (1997). Atheism, sex, and databases: The net as a social technology. In S. Kiesler (Ed.), Culture of the internet (pp. 35-52). Mahwah, NJ: Lawrence Erlbaum.

Stevens, J. P. (1992). Applied multivariate statistics for the social sciences (2nd ed.). Hillsdale, NJ: Lawrence Erlbaum.

Tammelin, M. (1998). From telepresence to social presence: the role of presence in a network-based learning environment. In S. Telia (Ed.). Aspects of media education: Vol. 8. Strategic imperatives in the information age (pp. 219-231). Helsinki, Finland: Media Education Centre, University of Helsinki, Media Education Publications.

Tu, C. H. (2000). On-line learning migration: from social learning theory to social presence theory in a CMC environment. Journal of Network and Computer Application, 23(1), 27-37.

$\mathrm{Tu}, \mathrm{C}$. H. (2002). The measurement of social presence in an online learning environment. International Journal of Educational Telecommunications, 1(2), 34-45.

Tu, C. H., \& Isaacs, M. (2002). An examination of social presence to increase interaction in online classes. American Journal of Distance Education, 16(3), 131-150.

Wegerif, R. (1998). The social dimension of asynchronous learning networks. Journal of Asynchronous Learning Networks, 2(1), 34-49, Retrieved October 26, 2003 from http://www.aln.org/publications/jaln/v2nl/pdf/ v2nl_wegerif.pdf. 